\title{
O épico e o trágico na história do $\mathrm{H}$ aiti \\ JACOB GORENDER
}

$\mathrm{N}$

ESTE PRECISO momento, em que escrevo a resenha de um livro notável sobre o H aiti, o país caribenho esteve assolado por uma rebelião sangrenta, que obrigou o presidente J ean Bertrand Aristide a abandonar o cargo e se refugiar no exterior. Em dois séculos de história, no entanto, A ristide foi o primeiro governante haitiano a exercer o poder após conquistá-lo pela via eleitoral, em 1994. Encontrava-se no segundo mandato, que não conseguiu completar, acusado de corrupção, de arbitrariedades e de violências.

No início do século XIX, o H aiti era a colônia mais produtiva das Américas e a primeira a conquistar a I ndependência nacio-

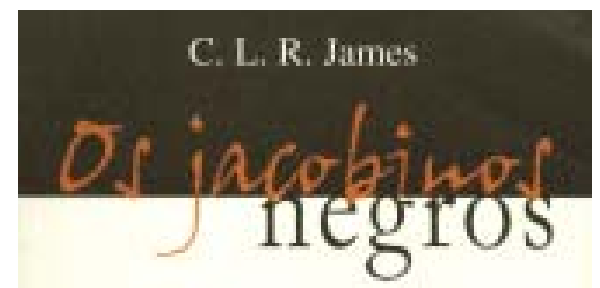

Tousaint L Oavertume carsvolaçlode Sio Domiages

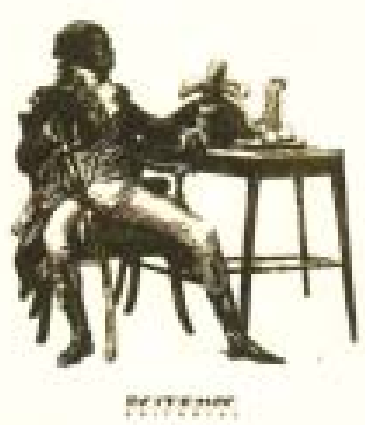
nal, em 1804. Como explicar então que não tenha tido uma trajetória progressista, mas, ao contrário, se tornasse o país mais pobre do continente, talvez um dos mais pobres do mundo?

Além de produzir café, anil, cacau, algodão e outros gêneros, o H aiti produzia sobretudo o açúcar, em condições mais competitivas do que as outras coIônias da época. N essa produção, empenhavam-se meio milhão de escravos, a maioria africanos, na proporção de dois terços.

O autor da obra aqui resenhada nos dá informação minuciosa, de leitura fluente, sobre as características da escravidão haitiana e sobre a guerra da I ndependência, ajudando-nos a encontrar a chave da indigência subseqüente do país. "O H aiti é aqui", escreveu Caetano Veloso, na letra de uma de suas canções. Seria o mesmo que escrevesse "a miséria é aqui", referindo-se, desta vez, ao Brasil.

Cyril Lionel Robert James (que costuma assinar suas obras como C.L.R. James) nasceu na ilha de Trinidad em 1901, onde veio a falecer em 1989. Teve o portunidade de receber educação acima da média dos conterrâneos, praticou 0 jornalismo, jogou críquete e escreveu sobre este esporte não só reportagens como também um livro (Beyond a Boundary), em 1963. 
Tinha interesses bastante diversificados e um deles, o mais importante, dirigia-se à política. $\mathrm{N}$ a I nglaterra, ligou-se ao I ndependent L abour Party e à IV Internacional, dirigida por L eon Trotski. Em Osjacobi nosnegrosjá se evidencia a adesão ao marxismo. N a década de 1950, foi atraído pelo nacionalismo africano, encarando-o como solução para a questão do negro. Em 1977, escreveu N krumah and the $G$ hana revolution, obra marcada por esta visão otimista. $M$ as 0 fracasso do nacionalismo africano levou-o a abandonar a política.

U $m$ dos livros mais conhecidos de C.L.R J ames é, precisamente, The Black J acobins Toussaint L'Ouverture and the San Domingo R evolution ${ }^{1}$. A Boitempo teve a feliz iniciativa de colocar a obra ao alcance do leitor brasileiro em tradução para o português, geralmente correta e elegante, assinada por Afonso Teixeira Filho².

$\mathrm{N}$ a verdade, esta é a segunda resenha que faço do livro de James. A primeira se insere no texto de $A$ escravidão reabilitada e se baseou na leitura da tradução italiana3. E sta, por sua vez, baseada na tradução portuguesa editada pela Boitempo, é mais extensa e detal hada.

James, o que não se deve censurar, manifesta entusiasmo incontido pelo episódio histórico que aborda. $\mathrm{N}$ ão obstante, semelhante entusiasmo o induz, no Preâmbulo datado de 1980, ao anacronismo de situar a rebelião dos escravos do $\mathrm{H}$ aiti, no começo do século XIX, ao nível dos movimentos operários da segunda metade do século XX. Argumenta que as reivindicações dos escravos seriam análogas às de um trabalhador contemporâneo ${ }^{4}$. Penso que se trata de equívoco. O s escravos podiam reivindicar dias de descanso, glebas para cultivo próprio de gêneros alimentícios, jornadas de trabalho menos estafantes etc. M asnão poderiam reinvindicar, como o trabalhador moderno, aumento de salário, remuneração conforme as tarefas cumpridas ou as peças produzidas, aposentadoria, previdência social etc. As rebeliões, no começo do século XIX, no continente americano, só podiam ter caráter antiescravista e anticolonialista. No mundo atual, o cenário internacional é sacudido pelas lutas anticapitalistas e antiimperialistas. Trata-se de etapas históricas profundamente diversas. $\mathrm{N}$ ão obstante, $\mathrm{O}$ anacronismo não prejudica o texto que se segue ao Preâmbulo.

À época dos acontecimentos que nos interessam, a ilha de São D omingos se dividia entre o domínio francês (que só mais tarde se chamaria H aiti) e o domínio espanhol. A ilha fora descoberta por Colombo, já na primeira viagem à América, e ele a denominou de $\mathrm{H}$ ispani ola. O s nativos foram completamente exterminados no processo da colonização européia.

O meio milhão de escravos negros, que labutavam nas plantagens e nos engenhos, era dominado por trinta mil brancos, incluindo os proprietários e seus auxiliares (feitores, técnicos, vigilantes etc.). Além dos negros e brancos, havia um segmento de poucos milhares de mulatos, já livres, mas submetidosa extorsões e agressões dos brancos escravo cratas. A pesar de tal desvantagem, vários mulatos espertos e ambiciosos conseguiam aproveitar as oportunidades de negócios e enriquecer. 
0 tratamento dado pelos escravistas aos seus servidores era terrivelmente cruel. A par do trabalho, que esgotava rapidamente as energias, pesavam sobre os escravos a alimentação escassa, a moradia sórdida e a inexistência de assistência médica. A labuta diária se processava durante longas jornadas, sob acionamento freqüente do açoite dos feitores. Q ualquer expressão recalcitrante era logo duramente castigada. 0 s mais indisciplinados sofriam o castigo de serem enterrados de pé, apenas com a cabeça de fora. Assim imobilizados, acabavam mortos depois de sofrer a horrível tortura de ter o rosto lentamente devorado pelos insetos e abutres.

0 regime escravista de São D omingos se identificava, sob muitos aspectos, com o brasileiro. Daí a relevância da obra de James para os estudiosos da historiografia de nosso País.

\section{O levante dos escravos}

A Convenção, constituída em Paris logo após a Revolução de 1789, proclamou a libertação dos escravos nas colônias francesas. A notícia da proclamação se propagou rapidamente em São D omingos. Em 1791, inicia-se a rebelião dos escravos, que abandonam as plantagens, destroem engenhos e agridem os brancos, matando vários proprietários. A rebelião não tem liderança definida e estabelece uma situação caótica na ilha. A liderança ea luta organizada só seriam concretizadas três anos depois, quando entra no processo rebelde um personagem com características privilegiadas para o papel histórico que desempenhou: Toussaint $B$ réda (nome depois cambiado para Toussaint L'O uverture). D oravante, em meu texto, será chamado simplesmente por Toussaint.

Antes da sua entrada em cena, um escravo chamado $M$ ackandal tentara acabar com o domínio dos brancos envenenando a água utilizada nas suas casas. M as, ao embriagar-se, fal ou demais e o denunciaram. Prenderam-no e o queimaram vivo ${ }^{5}$.

Toussaint era filho de um chefe tribal africano transferido como escravo para São D omingos. Ali, comprou-o um senhor dotado de al guma benevolência, que percebeu as qualidades intelectuais do novo escravo. D eu-Ihe a condição de capataz de uma turma de trabal hadores e uma esposa. D este conúbio nasceram oito filhos, o primogênito dos quais foi precisamente o personagem principal do livro de James.

0 mesmo senhor percebeu que o filho não era menos dotado do que o pai e Ihe conferiu certos privilégios, no contexto da condição de escravo. Pierre Baptiste, um velho negro instruído que morava na fazenda, alfabetizou o jovem e lhe ensinou a ler e a falar o francês culto (em vez do degradado francês crioulo coloquial). Transmitiu-Ihe princípios de geometria e desenho e ensinou-lhe rudimentos de latim.

Toussaint teve, então, a possibilidade de ler duas obras, que o influenciariam notavelmente. A primeira - o livro do Abade Raynal H istória filosófica e política do estabeleci mento e comércio dos eu ropeus nas duasí ndias. 
A bade Raynal fez uma descrição realista da situação nas colônias européias do Caribe, mostrando que a massa de escravos submetidos ao regime mais desumano de exploração se encontrava num ponto crítico, próximo de explosiva rebelião. A par com a condenação moral do regime escravista, afirmava que, para a rebelião ter início, faltava apenas uma liderança, o surgimento de um homem capaz de chefiar os escravos no caminho da revolta. "O nde está este homem?" perguntava o Abade. E respondia confiante: "ele, com certeza, surgirá" 6 .

Também teve influência marcante em Toussaint o livro de Júlio C ésar acerca da guerra contra os gauleses. O s comentários sobre as operações militares, na Roma da Antigüidade, forneceram ao futuro líder de tropas negras a concepção do que significavam as manobras militares em um confronto armado?.

Q uando resolveu mergulhar na batalha, em 1794, três anos depois de iniciada, Toussaint já contava com 45 anos, idade avançada para a época. Era baixote e feio, mas forte, e excepcionalmente habilidoso na arte de cavalgar. C asara com uma mulher que já tinha um filho e teve com ela um filho próprio. O cupava-se com a criação do gado e com o herbário da propriedade, o que lhe propiciou o aprendizado prático dos problemas de administração.

D otado de instrução bem acima dos ex-escravos, Toussaint não encontrou grandes obstáculos para ganhar ascendência entre eles e aglutinar um exército de combatentes sob o seu comando. Com uma tropa disciplinada e organizada, derrotou os exércitos dos franceses, dos espanhóis, que pretendiam apossar-se da parte francesa da ilha, e dos ingleses, preocupados com a contaminação que o exemplo da possessão francesa poderia produzir nas suas próprias possessões antilhanas.

Companheiros de Toussaint, destacaram-se na luta outros ex-escravos, como D essalines, $\mathrm{H}$ enri Christophe, $\mathrm{M}$ aurepas, Pétion e $\mathrm{M}$ oïse, um jovem sobrinho adotivo de Toussaint. Este último é considerado por James como a mais bem dotada figura da história mundial do período 1789-1815, com a exceção apenas de Bonaparte ${ }^{8}$.

Já vitorioso, Toussaint seguiu duas linhas de ação, que teriam conseqüências funestas para a sua liderança e para seu destino pessoal.

Em primeiro lugar, preocupou-se insistentemente em ganhar a confiança de Bonaparte, àquela altura primeiro cônsul do governo parisiense. Através de franceses aliados, enviou repetidas mensagens ao general chefe do consulado, insistindo na fidelidade à França e na concretização de uma aliança entre a R evolução Antilhana e a R evolução F rancesa. Bonaparte sequer tomou conhecimento desses bons propósitos, não somente porque se achava demasiado ocupado com as conquistas na E uropa, como principalmente porque tinha planos opostos aos dos ex-escravos no referente ao regime colonial.

Toussaint não conseguiu perceber que, da Convenção de 1789 ao consulado bonapartista, a R evolução Francesa infletiu para a direita, mudando as características do regime político no País, como também afastando-se da posição inicial com relação à escravidão nas colônias. 
A segunda questão, que influiu negativamente no destino de Toussaint, consistiu na decisão de manter a colônia como grande produtora de açúcar. 0 que se justificava, do ponto de vista da prosperidade econômica. $M$ as, para este fim, Toussaint não teve alternativa senão a de obrigar os ex-escravos a retornar ao trabalho compulsório nas fazendas. O s ex-escravos já eram homens livres do ponto de vista formal, mas estavam forçados a continuar a cultivar a cana e a produzir açúcar nas mesmas condições exaustivas de antes. A par disso, Toussaint manteve os brancos como proprietários, encarregados da direção e orientação da produção. J ames justifica tal decisão, lembrando que os bolcheviques, logo após a Revolução Soviética de 1917, também conservaram os especialistas burgueses, uma vez que não havia ainda operários capacitados para o comando técnico da produção. M ais uma vez, o autor desliza para o anacronismo, colocando um sinal de igualdade entre períodos e situações históricas muito diferenciadas 9 .

O s problemas a enfrentar pela liderança de Toussaint tinham o acréscimo da necessidade da vigilância com relação aos mulatos, que fizeram tentativas de alcançar o domínio da colônia, aproveitando a confusão da conjuntura.

0 confinamento nas fazendas, o trabalho compulsório imposto aos exescravos e a leniência para com os proprietários brancos minaram gravemente a posição de Toussaint e causaram descontentamento na ala esquerda dos rebeldes. Revolucionário radical, o seu sobrinho adotivo $\mathrm{M}$ oïse organizou e chefiou uma revolta contra a liderança. Aprisionado, Toussaint negou-lhe julgamento e 0 fuzilou sumariamente ${ }^{10}$. Privado da confiança dos trabalhadores negros, ficou debilitado para travar a batalha decisiva, que logo se seguiria.

\section{Toussaint e Leclerc}

Em 1801, Bonaparte interveio praticamente nos problemas concernentes à colônia francesa do Caribe. $\mathrm{N}$ ão só pretendia debelar o levante dos negros, como restabelecer a escravidão. Este último objetivo deveria ser mantido em segredo, até o momento favorável à sua implementação.

A intervenção se concretizou com o envio a São Domingos de uma expedição de 25 mil soldados sob o comando do próprio cunhado de Bonaparte, o general Leclerc, que viajou acompanhado da esposa Pauline, de músicos e fâmulos, como se tivesse em vista um evento festivo.

$M$ as, ao contrário de suas expectativas, defrontou-se com uma guerra sem tréguas. Toussaint reuniu as forças disponíveis e foi à luta. $\mathrm{N}$ esta se destacou principalmente D essalines. Ex-escravo, analfabeto, revelou maestria de grande chefe militar. N ão só maestria, como ferocidade. D iante da decisão do comandante francês R ochambeau de executar quinhentos negros, mandando enterrá-los num grande buraco, enquanto esperavam a execução, D essalines não vacilou e enforcou quinhentos brancos, para que o vissem Rochambeau e os brancos de Le Cap (hoje, Cabo Haitiano). Em conseqüência, o País sofreu tremenda devastação, reduzido a cinzas pelos incêndios ateados pelos combatentes do dois lados. 
Contando com uma tropa numerosa e bem equipada, Leclerc obteve êxitos iniciais. Diante da valentia dos negros, excedeu-se na prática de crueldades. C onseguiu aprisionar Toussaint, em agosto de 1802. L evado à França, não submeteram o líder negro a julgamento algum. Bonaparte decidiu livrar-se dele por meio do rigor do tratamento carcerário. No entanto, apesar de prisioneiro e maltratado, Toussaint ainda se declarava fiel à França e confiante em Bonaparte. E stava certo de que a escravidão nunca seria restaurada em $\mathrm{S}$. D omingos. $\mathrm{M}$ al alimentado, numa cela fria e sem aquecimento, sem tratamento médico, não resistiu à dureza do cárcere e, aos 57 anos, se extinguiu no dia 7 de abril de $1803^{11}$.

$M$ as 0 afastamento de Toussaint não trouxe a vitória para L eclerc. Além das perdas em combate, seu exército sofria baixas numerosas em conseqüência de doenças tropicais e, principalmente, da febre amarela. A metrópole francesa se viu obrigada a enviar um total de 34 mil soldados e, apesar disso, perdeu a colônia. 0 próprio L eclerc veio a falecer, em 1802, vítima da febre amarela.

D essalines, C hristophe, Clairveaux, M aurepas, Pétion e outros líderes negros prosseguiram o combate e conseguiram derrotar e expulsar o exército francês. $\mathrm{N}$ o processo da luta, massacraram a maioria dos brancos, que antes dominavam a colônia. Bonaparte conseguiu restabelecer a escravidão em outras possessões francesas, não, porém, na pátria de Toussaint.

\section{A Independência e seus problemas}

Enquanto, em Paris, a guilhotina decepava as cabeças do jacobinos, em São D omingos D essalines e seus companheiros continuavam a defender, de armas na mão, o ideal jacobino da liberdade e igualdade de todos os homens. Eles, os jacobinos negros, permaneciam fiéis ao espírito revolucionário da Convenção de 1789.

A 29 de novembro de 1803, os revolucionários negros divulgaram uma declaração preliminar de Indepen dência. A 31 de dezembro, foi lida a D eclaração de Independência definitiva. 0 novo Estado recebeu, no batismo, a denominação indígena de $\mathrm{H}$ aiti.

D essalines se tornou o primeiro chefe de Estado haitiano, sendo coroado imperador em outubro de 1804. M ercadores de Filadélfia o presentearam com uma coroa e um manto imperial trazido de Londres. Começou a governar com as bençãos dos capitalistas ingleses e americanos, como escreve J ames ${ }^{12}$.

O s ex-escravos, por sua vez, viram-se definitivamente livres do trabalho compulsório nas plantações de cana e nos engenhos de açúcar. Sob as presidências de Pétion e Boyer, passaram a se dedicar à tradição herdada da África, ou seja, à agricultura de subsistência. $\mathrm{O} \mathrm{H}$ aiti saiu do mercado mundial do açúcar e eliminou a possibilidade de progredir em direção a um nível econômico superior. D e colônia mais produtiva das A méricas passou a país independente pauperizado e fora de um intercâmbio favorável na economia internacional.

O autor de Osjacobinos negros acrescentou, em data não especificada, um apêndice intitulado De Toussaint L'O uverture a Fidel Castro. Compendiou aí a 
história do $\mathrm{H}$ aiti posterior à conquista da Independência. $\mathrm{H}$ istória conturbada, que inclui, em 1913, a invasão por fuzileiros navais americanos e a ditadura (19571971) de François D uvalier, cujos esquadrões da morte instauraram um regime de terror e assassinatos no País. A pelidado de Papa D oc, François D uvalier foi sucedido no Governo pelo filho, Claude D uvalier, o Baby D oc, forçado a sair do País em $1986^{13}$.

Sobre Fidel C astro, a posição de James é evasiva, expressa em afirmações breves, frias e pouco definidas ${ }^{14}$.

As dificuldades do $\mathrm{H}$ aiti não se deveram, com o passar do tempo, somente ao domínio da agricultura de subsistência e à ausência de perspectivas econômicas mais elevadas. D everam-se também, e não menos, à quarentena, que Ihe impuseram até mesmo as nações latino-americanas recém-emancipadas. Q uando exilado, Simon Bolivar encontrou abrigo no $\mathrm{H}$ aiti, onde recebeu de Pétion proteção, ajuda financeira, dinheiro, armas e até uma prensa tipográfica. No entanto, Simon Bolivar excluiu o $\mathrm{H}$ aiti dos países latino-americanos convidados à Conferência do Panamá, em 1826. 0 isolamento internacional acentuou o atraso e agravou as dificuldades históricas, após uma das mais heróicas lutas emancipadoras do hemisfério ocidental ${ }^{15}$.

C. L. R. J ames expressa a opinião de que as I ndias 0 cidentais alcançaram um desenvolvimento econômico e cultural notável e que sua população possui qualificação e identidade suficientes para que seja sugerido, como ele 0 faz, a criação de um Estado unificador de todas elas.

\section{N otas}

1 A primeira edição é de 1938. A edição inglesa, que tenho em mãos, é de 1994 e foi inicialmente publicada em 1980, na Grã-Bretanha, por Allison \& Busby.

2 C. L. R. James, Os jacobinos negros. Toussaint L'O uver ture e a revolução de São D omingos, São Paulo, Boitempo, 2000. A editoração é de ótima qualidade, apesar de uns poucos senões, como, por exemplo, o de omitir, no índice onomástico e remissivo, precisamente a rubrica referente a Toussaint, o personagem central do livro e, de longe, como seria de esperar, o mais citado.

3 Cf. Jacob Gorender, A escravidão reabilitada, São Paulo, Ática, 1990, pp. 130-132; C. L. R. James, I Giacobini N eri. La Prima Rivolta contro I'U omo Bianco, M ilano, Feltrinelli, 1968.

4 C. L. R. James, op. cit., p. 13.

$5 \mathrm{M}$ ackandal é personagem do livro de Alejo Carpentier EI R eino de este $M$ undo, do qual há tradução para o português. Cf. J ames, op. cit, pp. 34-35.

6 Cf. James, op. cit., pp. 38-39.

7 Júlio César. Commentarii de Bello Gallico. A pud James, op. cit., p. 96.

8 Cf. James, op. cit, p. 18. 
9 I dem, pp. 258-259.

10 I dem, pp. 253-254.

11 I dem, pp. 328-331.

12 I dem, p. 335.

13 I dem, pp. 361-363 e 386.

14 I dem, pp. 344-372.

15 Idem, p. 364; Gorender, op. cit., pp. 131-132.

Resumo - o Auto r apresenta uma resenha crítica do livro de C. L. R. James, editado, no B rasil, pela Boitempo, intitulado O sjacobinosnegros. Tou ssaint L'O u ver tureea revolução eSão D omingos. J ames narra e anal isa a rebelião dos escravos da colônia francesa situada na ilha de São Domingos, no final do século XVIII, como conseqüência da ação da C onvenção surgida da Revolução Francesa de 1789, a qual proclamou a emancipação dos escravos. N essa rebelião, o autor destaca a ação do líder negro Toussaint L 'O uverture, que, após derrotar exércitos da França, Espanha e Inglaterra, ganhou o domínio da colônia francesa. Em seguida, a obra de J ames se detém na determinação de Bonaparte de restaurar a escravidão e o envio da força expedicionária francesa comandada por L eclerc. Toussaint L'O uverture viria a ser derrotado e aprisionado. Seus companheiros, D essalines e outros, os jacobinos negros, prosseguiram o combate e conquistaram, em 1804, a Independência definitiva, batizando o País com o nome nativo de H aiti. Da Independência decorreram problemas que se prolongam até os dias atuais.

\begin{abstract}
THE AUth or presents a critical review of C.L.R. James' book Theblack J acobins. Toussaint L'O uvertureand theSan D omingo revolution (published in Brazil by Boitempo). James narrates and analyzes the late $18^{\text {th }}$ century slave rebellion in the French colony located in the island of San Domingo as a consequence of the measures taken by the Convention, established after the French Revolution, which emancipated slaves. The author highlights the activities of black leader Toussaint L'O uverture in the uprising, who after defeating the armies of France, Spain and England, won the governance of the former French colony. James also examines Bonaparte's determination to restore slavery and his decision to send a French expeditionary force commanded by Leclerc that would defeat and imprison Toussaint L'O uverture - whose companions, D essalines and others, the Black J acobins, would continue to fight. E ventually, in 1804, they achieved definite independence, baptizing the country with the native name of $\mathrm{H}$ aiti, but the problems that ensued endure to this day.
\end{abstract}

J acob Gorender é historiador, autor, entre outros livros, de 0 escravismo colonial e Combatenastrevas(Ática). Foi professor-visitante do IEA-U SP.

Texto recebido e aceito para publicação em 8 de março de 2004. 